\title{
Fly ash-mediated formation of polychlorinated naphthalenes during secondary copper smelting and mechanistic aspects
}

\author{
Xiaoxu Jiang, Guorui Liu*, Mei Wang, Minghui Zheng* \\ State Key Laboratory of Environmental Chemistry and Ecotoxicology, Research Center for Eco-Environmental Sciences, Chinese Academy of Sciences, P.O. Box 2871, Beijing \\ 100085, China
}

\section{H I G H L I G H T S}

- High concentrations of PCNs were formed via thermal reactions on fly ash.

- More chlorinated homologs were dominant in the formed PCNs.

- Chlorination of naphthalene is identified as an important PCN formation mechanism.

- A congener-specific pathway from naphthalene to octachloronaphthalene is proposed.

\section{A R T I C L E I N F O}

\section{Article history:}

Received 17 June 2014

Received in revised form 15 September 2014

Accepted 17 September 2014

Available online 17 October 2014

Handling Editor: Caroline Gaus

\section{Keywords:}

Polychlorinated naphthalenes

Secondary copper smelting

Kinetics

Chlorination

Formation pathway

\begin{abstract}
A B S T R A C T
Thermal experiments (at $250-450{ }^{\circ} \mathrm{C}$ for $10-240 \mathrm{~min}$ ) on fly ash from secondary copper smelting process $(\mathrm{SeCu})$ were performed to study the polychlorinated naphthalene (PCN) formation in the post-zone of a secondary copper smelter. Unexpectedly high concentrations of PCNs were formed. Total PCN concentrations and toxic equivalents were 47-104 and 44-80 times higher than the initial concentration and toxic equivalent, respectively. The thermal disposal of SeCu fly ash should therefore be reconsidered. The kinetic of each homolog was determined under different thermal conditions. Less chlorinated homologs favored $350^{\circ} \mathrm{C}$ and more chlorinated homologs favored higher temperature. Most of the homologs reached an equilibrium of formation and degradation within $30 \mathrm{~min}$, except octachloronaphthalene which did not appear to reach such an equilibrium even after $240 \mathrm{~min}$. Chlorine substitution of the formed PCNs was identified and a similar pattern was found in chlorination products starting with naphthalene and chlorine. Furthermore, inorganic chlorine and unsubstituted naphthalene were found in the reaction products, confirming that the formation of naphthalene and the chlorination of that naphthalene could occur and could be suggested to be an important PCN formation route. A detailed formation pathway from naphthalene through octachloronaphthalene is proposed.
\end{abstract}

() 2014 Elsevier Ltd. All rights reserved.

\section{Introduction}

Polychlorinated naphthalenes (PCNs) are candidates for inclusion in the Persistent Organic Pollutant Protocol of the United Nations Economic Commission for Europe (Lerche et al., 2002) and it has been proposed that they be included in Annexes A, B, and/or $C$ of the Stockholm Convention. There is growing public concern about the formation and emission of PCNs. Unintentional emissions from industrial activities are currently considered to be the main sources of PCNs because industrial applications of PCNs have ceased in many countries (Falandysz, 1998). PCNs are always

* Corresponding authors. Tel.: +86 106284 9172; fax: +86 1062923563 (M. Zheng).

E-mail addresses: grliu@rcees.ac.cn (G. Liu), zhengmh@rcees.ac.cn (M. Zheng). emitted from thermal-related industries along with polychlorinated dibenzo-p-dioxins (PCDDs), polychlorinated dibenzofurans (PCDFs), and polychlorinated biphenyls, and these chemicals all have similar physicochemical properties, biological effects, and toxic mechanisms (Hanberg et al., 1990).

In municipal incineration processes, PCNs may be formed from polycyclic aromatic hydrocarbons through similar de novo pathways to those that produce PCDFs (Iino et al., 1999; Imagawa and Lee, 2001; Weber et al., 2001; Oh et al., 2007). Kim and coworkers found that PCNs could be formed by the coupling of chlorinated phenoxy radicals (formed from chlorophenol) at high temperatures (Kim et al., 2005, 2007). It has also been suggested that chlorination reactions are involved in PCN formation during thermal-related process (Imagawa and Lee, 2001; Jansson et al., 2008; Liu et al., 2010). The industrial production of PCNs was achieved by 
chlorinating molten unsubstituted naphthalene using chlorine gas in the presence of transition metal chlorides (Schneider et al., 1998). The further chlorination of the resulting PCNs is of particular interest because the most toxic congeners are chlorinated at the lateral positions. Determining the factors that govern the addition of chlorine to PCNs may facilitate the control of these toxic chemicals in industrial exhausts and residues. Chlorination can be catalyzed by transition metal species, especially copper compounds, which are known to have strong catalytic effects (Ryu et al., 2013). In a recent study, Ryu et al. (2013) determined the congener patterns of the chlorinated products that were produced when unsubstituted naphthalene was chlorinated using a mixture of copper(II) chloride and silicon dioxide as a matrix.

In addition to municipal solid waste incinerators (MSWIs) (Abad et al., 1999; Jansson et al., 2008; Hu et al., 2013), various metallurgical industries, particularly $\mathrm{SeCu}$, are becoming increasingly important sources of PCNs (Ba et al., 2010; Nie et al., 2011; Liu et al., 2012a,b). Liu et al. (2014) summarized PCN emission factors and annual emissions for 14 industrial thermal processes, and suggested that $\mathrm{SeCu}$ potentially contributes a large proportion of PCN emissions in China, having comparable emission factors to those found for MSWIs. However, no attempt was made currently to determine the detailed PCN patterns and formation pathways that led to the observed PCN emissions from SeCu or other metallurgical processes. Despite the intensive presence of PCNs and toxic effects PCNs can have, the PCN emissions from $\mathrm{SeCu}$ have been studied much less than MSWI emissions in the past.

This study builds on previous work, and was conducted to gain a first insight into the PCN formation mechanisms during $\mathrm{SeCu}$. A laboratory-scale system using $\mathrm{SeCu}$ fly ash as a reaction matrix was used to simulate the thermal reactions that produce PCNs during $\mathrm{SeCu}$ under controlled, realistic conditions. The main goal of this work was to characterize the homolog and congener patterns of the PCNs that are generated during simulated thermal processes using SeCu fly ash and to identify the underlying mechanisms that are responsible for producing the PCNs. The kinetics involved in the formation of the total PCNs and the mono- to octa-chlorinated naphthalenes (mono- to octa-CNs) were also determined in detail. The results may allow methods for controlling PCN emissions during metallurgical processes to be developed.

\section{Materials and methods}

\subsection{Experimental design}

It is widely recognized that fly ash is a matrix on which heterogeneous catalyzed reactions occur, so it was used as the matrix for the thermal experiments described here, offering the advantage that as close as possible to a "real" active surface (Milligan and Altwicker, 1993; Addink and Olie, 1995; Pekárek et al., 2007). Fly ash was collected from a reverberatory furnace of a secondary copper smelter in eastern China. The production capacity of each furnace in the smelter was 110 t. Fly ash has a complex composition, so to allow us to understand the nature of the fly ash used in the study, its inorganic and organic components and surface properties were determined using inductively coupled plasma optical emission spectrometry (using an Optima 8300 instrument; Perkin Elmer, Waltham, MA, USA), scanning electron microscopy with energy dispersive X-ray spectrometry (using a S-3000N instrument; Hitachi, Tokyo, Japan), and an ASAP 2400 system (Micromeritics, Norcross, GA, USA) and the specific surface areas of the materials were calculated using the BET model. High concentrations of carbon, chlorine, oxygen, and metals such as $\mathrm{Zn}, \mathrm{Ca}, \mathrm{Pb}$, $\mathrm{Al}$, and $\mathrm{Fe}$ were found on the fly ash surface, and the $\mathrm{Cu}$ concentration was particularly high $\left(262.4 \mathrm{mg} \mathrm{g}^{-1}\right)$. The SeCu fly ash was compared with fly ash from other thermal-related processes, and it was found that the $\mathrm{Cu}$ concentration was much higher in the $\mathrm{SeCu}$ fly ash than in fly ash from a MSWI plant $\left(0.47-0.33 \mathrm{mg} \mathrm{g}^{-1}\right)$ (Cobo et al., 2009) and fly ash from an integrated iron and steel facility $\left(0.12-7.95 \mathrm{mg} \mathrm{g}^{-1}\right.$ ) (Tsai et al., 2007). PCNs are usually formed along with PCDDs and PCDFs, and the formation of all of these chemicals is probably favored by the presence of carbon, chlorine, and transition metals, such as $\mathrm{Cu}$, on the surfaces of fly ash particles (Addink and Olie, 1995; Hatanaka et al., 2004; Stanmore, 2004; Chin et al., 2011). Therefore, we speculated that the fly ash we had prepared could lead to the formation of PCNs under favorable conditions. The fly ash had a high surface area obviously mean that the surface and external reactants involved in reactants could easily come into contact with each other (Milligan and Altwicker, 1993). The detailed fly ash characterization information is given in Tables S1-S3.

The PCN formation process was modeled at the laboratory scale. The fly ash was placed as a fixed bed to simulate collected ash particles in a SeCu plant, and an air stream was passed through the fixed bed. The PCN concentrations found at different temperatures and/or times have been determined in some previous studies, whereas the PCN concentrations found after only one or two selected reaction times have been determined in other studies. The temperatures $250{ }^{\circ} \mathrm{C}, 350{ }^{\circ} \mathrm{C}$, and $450{ }^{\circ} \mathrm{C}$ were used in this study because that range covers the temperatures at which PCNs could form in the cooling zone of a real plant. PCDDs and PCDFs can, theoretically, form rapidly (Altwicker et al., 1992), and the residence time of fly ash particles in the post-combustion zone can be hours (Addink and Olie, 1995), so laboratory tests with reaction times of several minutes to hours were used to validate the kinetic models and identify relationships between PCN formation and residence time.

The simulation system was a quartz tube reactor $(60 \mathrm{~cm}$ long and $4.5 \mathrm{~cm}$ in diameter) within a tube furnace that provided even heating and precise temperature control. A schematic of the reaction system used is shown in Fig. S1. An even layer of fly ash $(0.2 \mathrm{~g})$ was placed on a porcelain boat in the reactor and the system was heated to 250,350 , or $450{ }^{\circ} \mathrm{C}$ for $10,30,120$, or $240 \mathrm{~min}$ (as shown in Table S4). The air stream was kept at a constant flow rate of $50 \mathrm{~mL} / \mathrm{min}$ to simulate the open system in a $\mathrm{SeCu}$, and was left running for $30 \mathrm{~min}$ after the end of the heating to trap products diffused into the gas phase. The outlet gas was quenched as soon as it left the reactor by passing it through three absorption bottles each containing $50 \mathrm{~mL}$ of toluene, which were cooled in ice.

\subsection{Analytical methods}

The toluene from the traps and the fly ash residues were analyzed for PCNs by isotope dilution high resolution gas chromatography and high resolution mass spectrometry (HRGC/HRMS) (Ba et al., 2010; Liu et al., 2010). The toluene from the traps and residues were spiked with a mixture of ${ }^{13} \mathrm{C}_{10}$-labeled PCN internal standards (ECN-5102, ${ }^{13} \mathrm{C}_{10}-\mathrm{CN}-27,-42,-52,-67,-73$, and -75 ; Cambridge Isotope Laboratories, Andover, MA, USA). Each residue sample was digested in hydrochloric acid, freeze-dried, then Soxhlet extracted with $250 \mathrm{~mL}$ of toluene for $24 \mathrm{~h}$. Each residue extract and sample of toluene from the traps was cleaned by passing it through a series of chromatographic columns (an acidified silica gel column, a multilayer silica gel column, then a basic alumina column). The cleaned extract was then concentrated, by rotatory evaporation and then under a gentle stream of nitrogen, to about $20 \mu \mathrm{L}$. The initial PCN concentration in the fly ash had to be determined so that the PCNs formed in the reaction system could be determined, so the original fly ash was analyzed using the same method as was used for the solid residues. 


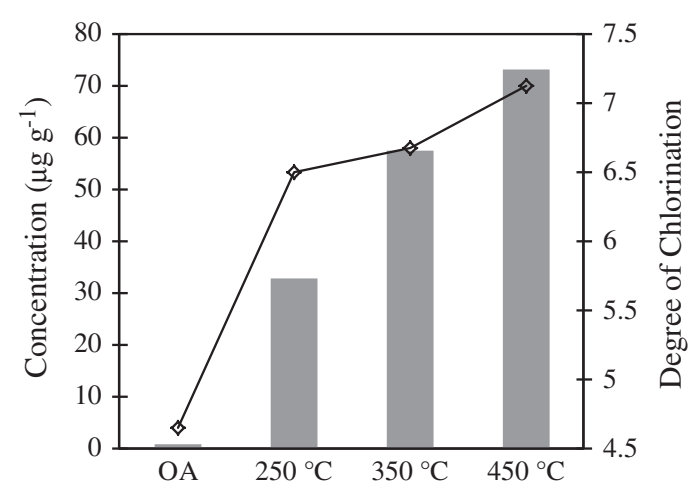

Fig. 1. Total polychlorinated naphthalene concentrations (bars) and degree of chlorination (line) in the products of thermal experiments at $250-450{ }^{\circ} \mathrm{C}$ and in the original fly ash (OA: original fly ash).

Before each extract was analyzed by HRGC-HRMS, a ${ }^{13} \mathrm{C}_{10}$-labeled PCN standard (ECN-5260, containing ${ }^{13} \mathrm{C}_{10}-\mathrm{CN}-64$; Cambridge Isotope Laboratories) was added, to allow the $\mathrm{PCN}$ recoveries to be calculated. All 75 PCN congeners were analyzed using an Agilent 6890 high resolution gas chromatograph (Agilent Technologies, Santa Clara, CA, USA), equipped with a DB-5 MS fused-silica column ( $60 \mathrm{~m}$ long, $0.25 \mathrm{~mm}$ i.d., $0.25 \mu \mathrm{m}$ film thickness; Agilent Technologies, Santa Clara, CA, USA), coupled to a DFS MS instrument (Thermo Fisher Scientific, Waltham, MA, USA), which was operated in selective ion monitoring mode. The two most intense characteristic $m / z$ ratios were monitored for each PCN homolog group.

\subsection{Quality control and assurance}

A blank test was performed after every three sample tests to determine the PCNs produced when reactants were not present. The reactor was kept at $350{ }^{\circ} \mathrm{C}$ for $10 \mathrm{~min}$ for a blank test, and the gas passed through the system was collected as for a sample. The PCN concentrations found in the toluene traps from all of the blank tests were less than $0.8 \%$ of the concentrations found in toluene traps from the sample tests, so no blank correction was required. Experiment 1, in which the middle reaction temperature and time were used, was performed in triplicate. The PCN concentrations in the triplicate sample media were within $20 \%$ of each other.

The PCN peaks were identified from their retention times compared with available individual PCN standards, ion ratios and by taking into consideration the PCN elution order on the DB-5 column. The recoveries of the ${ }^{13} \mathrm{C}_{10}$-labeled $\mathrm{PCN}$ congeners relative to the labeled injection standard were $30-123 \%$ for both matrices.

\section{Results and discussion}

\subsection{PCN concentrations}

The amounts of PCNs in the vapor phase (i.e., in the toluene trap) and the residue were compared, and more than $99.5 \%$ of the total PCN concentration was found in the vapor phase. This confirmed that the PCNs volatilized during the tests (that is, the PCNs could be transferred from the solid matrix to the gas phase when the fly ash was heated). It is, therefore, reasonable to use the vapor phase PCN concentration, rather than the sum of the PCN concentrations in the two phases, in the subsequent assessments related to the formation of PCNs.

The PCN concentrations found in the vapor phase produced during the thermal reaction tests under the different test conditions are shown in Figs. 1 and 2. Unexpectedly large amounts of PCNs, $33.40-73.94 \mu \mathrm{g} \mathrm{g}^{-1}$, were found to be produced during the thermal treatments, and the highest PCN yield was more than two orders of magnitude higher than the PCN concentration in the initial fly ash $\left(0.708 \mu \mathrm{g} \mathrm{g}^{-1}\right)$. These results indicate that the SeCu fly ash strongly promoted the formation of PCNs during the thermal reactions.

The dioxin-like toxicities of PCNs have been investigated previously (Hanberg et al., 1990; Blankenship et al., 2000; Villeneuve et al., 2000), and the relative potency factors that relate individual PCN congeners to 2,3,7,8-tetrachlorodibenzo-p-dioxin that were estimated in those studies were used to evaluate the toxicity of the PCNs found in this study (Noma et al., 2004; Liu et al., 2010). The PCN toxic equivalent (TEQ) for a sample was defined, in this study, as the sum of the concentration of each congener multiplied by the relative potency factor for that congener, determined by Noma et al. (2004). The PCN TEQs in the products were 36.3848.41 TEQ ng/g, which were 44-80 times higher than the initial PCN TEQs. Taking this amplification of the toxicity of PCNs in SeCu fly ash into consideration, the thermal disposal of fly ash (such as recycling in furnaces) in some $\mathrm{SeCu}$ plants and in other metallurgical plants should be reconsidered and reevaluated to decrease the potential for contaminating the environment.

The PCN concentrations were different when different reaction conditions were used. The PCN yield increased remarkably, from 33.40 to $73.94 \mu \mathrm{g} \mathrm{g}^{-1}$, as the temperature was increased from 250 to $450{ }^{\circ} \mathrm{C}$. Fig. 1 shows the relationship between the temperature and the total PCN concentration and the degree of chlorination (the average number of chlorine atoms in each molecule). In general, the degree of chlorination increased as the temperature was increased, which indicated that the chlorination reaction was more favored at higher temperatures within the range 250$450{ }^{\circ} \mathrm{C}$. The amount of PCNs formed as a function of time (Fig. 2) followed a similar trend to that found using fly ash from a municipal waste incinerator (Schneider et al., 1998). It can be seen from Fig. 3 that the amount of PCNs formed had increased after a short reaction time (less than $30 \mathrm{~min}$ ), and the amount formed was the same (52.29-58.04 $\mathrm{gg} \mathrm{g}^{-1}$ ) even after longer reaction times (up to $240 \mathrm{~min}$ ). Notably, the homologs with different degrees of chlorination peaked at different temperatures and times, the details of which are presented and discussed next.

\subsection{Homolog profiles}

The dominant homologs in the initial fly ash were the pentachloronaphthalenes (penta-CNs), heptachloronaphthalenes (hepta-CNs), and hexachloronaphthalenes (hexa-CNs), which contributed $21.8 \%, 19.0 \%$, and $18.1 \%$ of the total PCN concentration, respectively. However, the PCN profile had changed significantly

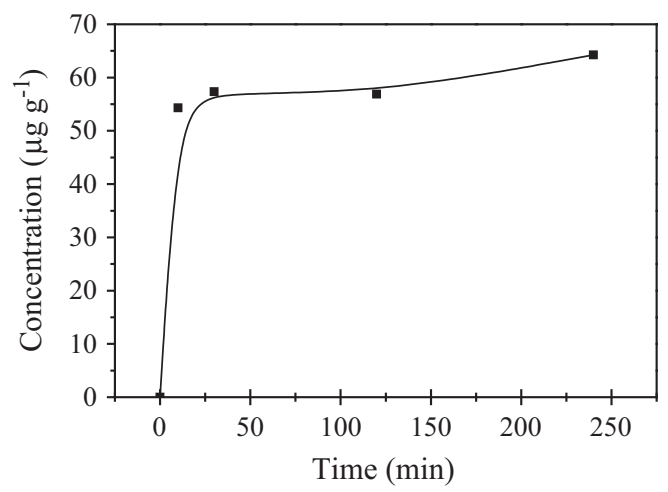

Fig. 2. Total polychlorinated naphthalene concentrations after different thermal treatment times. 

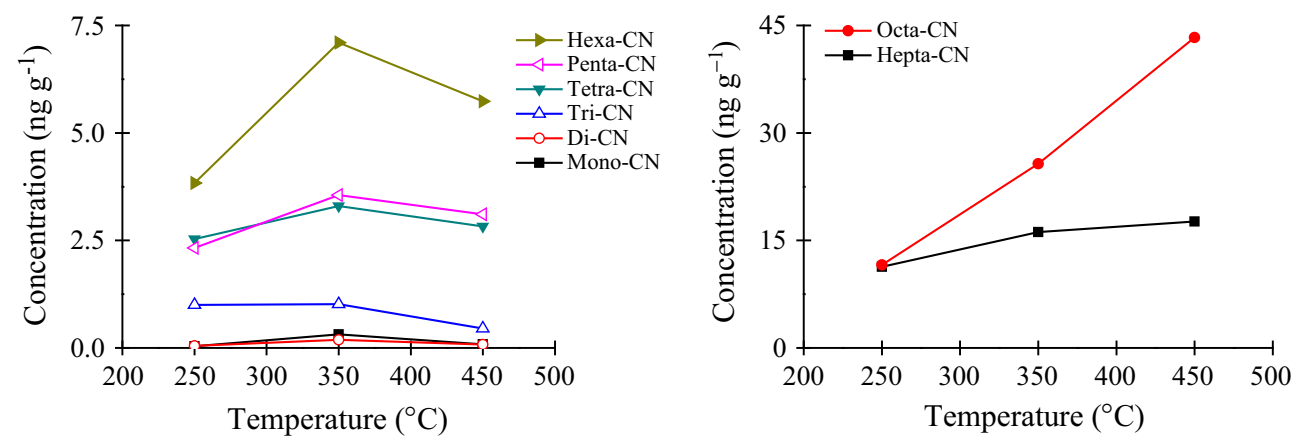

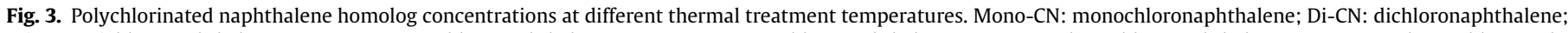

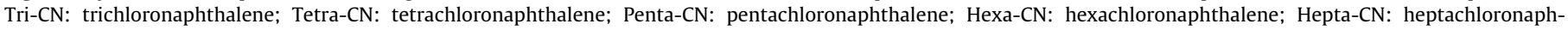
thalene; Octa-CN: octachloronaphthalene.

after the fly ash had been treated, and octachloronaphthalene (octa$\mathrm{CN}$ ) was the most abundant homolog in all of the tests, accounting for $35.4-59.1 \%$ of the total PCN concentrations. Hepta-CN was the second most abundant homolog in the tests, contributing 23.8$34.7 \%$ of the total PCN concentrations. The penta-CN and hexa-CN contributions to the total PCN concentrations decreased to 4.2$7.1 \%$ and $7.8-11.3 \%$, respectively, after the tests. These results demonstrate that heating the fly ash caused the more chlorinated homologs to become dominant, even though the less chlorinated homologs had initially been dominant in the fly ash. This obvious transformation from less chlorinated homologs dominating to more chlorinated homologs dominating suggests that a chlorination reaction, changing less chlorinated congeners into more chlorinated congeners, may contribute to the formation of PCNs in thermal treatments.

The homolog profiles changed noticeably within the temperature range $250-450{ }^{\circ} \mathrm{C}$. Fig. 3 shows that the concentration of the less chlorinated homologs (mono-CNs to hexa-CNs) peaked at $350{ }^{\circ} \mathrm{C}$ but that the concentrations of the more chlorinated homologs (hepta-CNs and octa-CN) increased continuously as the temperature was increased. These results indicate that the production of the less chlorinated homologs was favored at $350^{\circ} \mathrm{C}$, which may have been caused by the mechanism involved having its lowest activation energy at $350^{\circ} \mathrm{C}$. The production of the more chlorinated homologs was favored at higher temperatures (possibly even higher than $450^{\circ} \mathrm{C}$ ), implying that the mechanism involved may have a lower activation energy at such high temperatures.

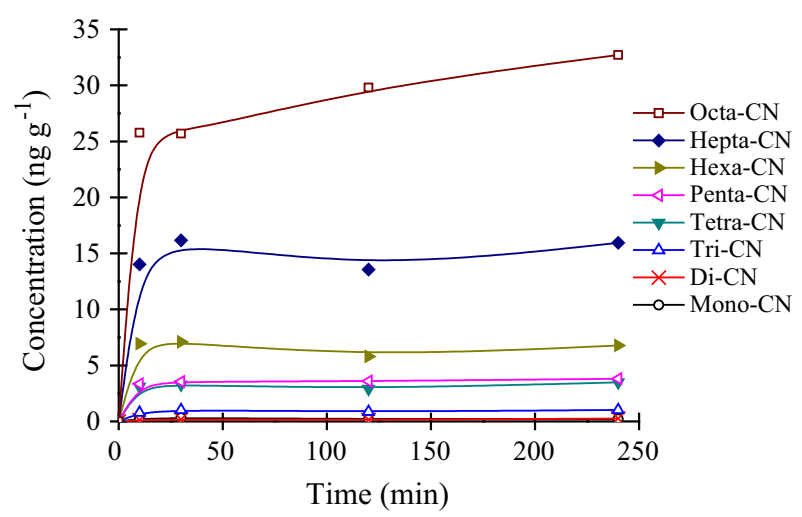

Fig. 4. The time dependences of the polychlorinated naphthalene homolog concentrations. Mono-CN: monochloronaphthalene; Di-CN: dichloronaphthalene; Tri-CN: trichloronaphthalene; Tetra-CN: tetrachloronaphthalene; Penta-CN: pentachloronaphthalene; Hexa-CN: hexachloronaphthalene; Hepta-CN: heptachloronaphthalene; Octa-CN: octachloronaphthalene.
The kinetics of the formation of the mono to octa-CNs in terms of the net concentrations of each (the difference between the total concentration and the initial concentration are presented in Fig. 4. The highest concentrations of most of the homologs (mono-CNs to hepta-CNs) were reached within 30 min of heating, whereas the most chlorinated homolog, octa-CN, continued to be formed until $240 \mathrm{~min}$. These phenomena suggest that PCN formation and degradation processes may have occurred on the fly ash simultaneously. The formation of all the homologs was dominant at the beginning of the heat treatment, and the formation and degradation of most of the homologs reached an equilibrium within $30 \mathrm{~min}$. Only octa$\mathrm{CN}$ did not appear to reach such an equilibrium.

The mechanistic relationships between each of the PCN homologs were investigated by determining the Pearson correlation coefficient $(R)$ for the relationships between each of the PCN homologs. It can be seen from Table S5 that adjacent PCN homolog groups were closely related to each other. Similar results were found in a previous study performed by Oh et al. (2007), who found that adjacent PCN homologs were closely related to each other when municipal waste incineration was simulated. This correlation analysis provided another support for the chlorination pathway suggested above being responsible for PCN formation.

\subsection{Congener patterns}

The concentration of each congener was expressed as a fraction of the concentration of its entire homolog group (see Fig. 5), to make identifying the PCN congener distribution patterns easier to achieve. The substituent position numbers for PCNs are shown in Fig. S2. The congener patterns were used because they offer a detailed "fingerprint" of the PCN pattern, potentially allowing the identification of the sources of the PCNs produced from thermal formation on fly ash from $\mathrm{SeCu}$.

The congener patterns were unexpectedly similar to the patterns that have been found when naphthalene has been chlorinated, as reported by Schneider et al. (1998), who determined the congener patterns in industrial PCN products that had been produced by chlorinating molten naphthalene using chlorine gas in the presence of a transition metal chloride. The dominant congeners in each homolog in industrial PCN products and in the products formed in our study are shown in Table 1. It can clearly be seen that the PCNs in both the industrial products and this study had a specific congener pattern, with chlorine substituents usually present at the 1 and 4 positions and the 2, 5, 6, and 8 positions often being attacked by chlorine atoms. This suggests that the industrial products and the products of this study may share the same formation pathway, which supports the idea that the PCNs found in this study were formed through the chlorination pathway 


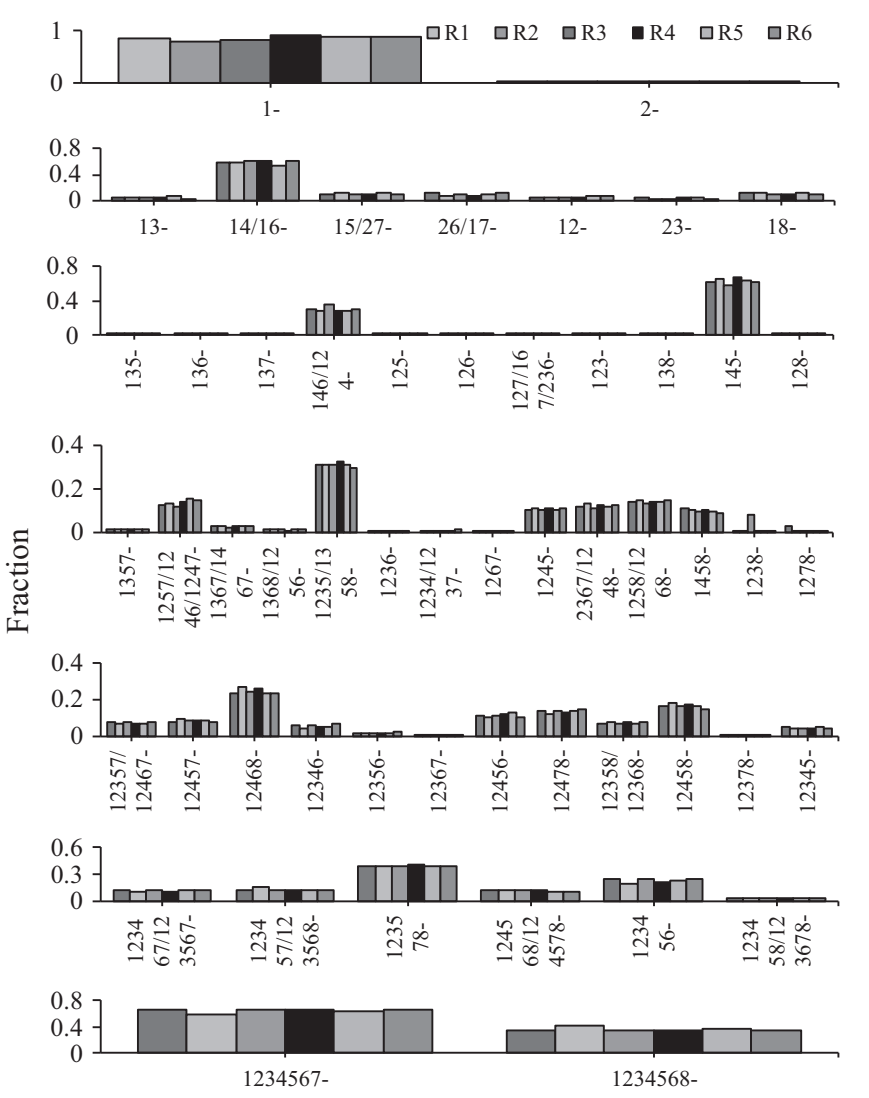

Fig. 5. Polychlorinated naphthalene congener distribution patterns in the thermal treatment samples (the congener concentration is shown relative to its total homolog concentration, as a wt\%). R1: $30 \mathrm{~min}, 350^{\circ} \mathrm{C}$; R2: $30 \mathrm{~min}, 250^{\circ} \mathrm{C}$; R3: $30 \mathrm{~min}, 450^{\circ} \mathrm{C}$; R4: $10 \mathrm{~min}, 350^{\circ} \mathrm{C}$; R5: $120 \mathrm{~min}, 350^{\circ} \mathrm{C}, \mathrm{R} 6: 240 \mathrm{~min}, 350{ }^{\circ} \mathrm{C}$.

Table 1

Dominant polychlorinated naphthalene congeners in Halowax and generated in thermal treatments.

\begin{tabular}{lll}
\hline Homolog & Halowax (Schneider et al., 1998) & Formation in fly ash \\
\hline Mono-CN $^{\mathrm{a}}$ & 1 & 1 \\
Di-CN $^{\mathrm{b}}$ & $1,4 / 1,6$ & $1,4 / 1,6$ \\
Tri-CN $^{\mathrm{c}}$ & $1,4,6 ; 1,4,5$ & $1,4,6 / 1,2,4 ; 1,4,5$ \\
Tetra-CN $^{\mathrm{d}}$ & $1,2,5,7 / 1,2,4,6 / 1,2,4,7 ; 1,2,6,8$ & $1,2,5,7 / 1,2,4,6 / 1,2,4,7 ;$ \\
& & $1,2,3,5 / 1,3,5,8 ; 1,2,5,8 / 1,2,6,8$ \\
Penta-CN $^{\mathrm{e}}$ & $1,2,4,6,8 ; 1,2,4,5,8$ & $1,2,4,6,8 ; 1,2,4,5,8$ \\
Hexa-CN $^{\mathrm{f}}$ & $1,2,4,5,6,8 / 1,2,4,5,7,8$ & $1,2,3,5,7,8 ; 1,2,3,4,5,6$ \\
Hepta-CN $^{\mathrm{g}}$ & $1,2,3,4,5,6,8$ & $1,2,3,4,5,6,7 ; 1,2,3,4,5,6,8$ \\
\hline
\end{tabular}

a Mono-CN: monochloronaphthalene.

b Di-CN: dichloronaphthalene.

c Tri-CN: trichloronaphthalene.

d Tetra-CN: tetrachloronaphthalene.

e Penta-CN: pentachloronaphthalene.

f Hexa-CN: hexachloronaphthalene.

g Hepta-CN: heptachloronaphthalene.

starting from naphthalene. The PCN congener patterns found in this study were also very similar to the congener patterns found in PCNs synthesized in the laboratory using the chlorination reaction starting from naphthalene and catalyzed by $\mathrm{CuCl}_{2}$ (Ryu et al., 2013). This offers greater support for the chlorination pathway being responsible for the formation of PCNs in our study. As mentioned above, the chlorination reaction can be catalyzed by transition metals. An aromatic molecule such as naphthalene can be directly chlorinated through the route shown in Eqs. (1) and (2) (Stieglitz et al., 1989; Takaoka et al., 2005; Ryu et al., 2013). The Deacon reaction can transform $\mathrm{HCl}$ into $\mathrm{Cl}_{2}$ and result in chlorination catalyzed by the transition metal (see Eq. (3)) (Gullett et al., 1992).

$$
\begin{aligned}
& \mathrm{ArH}+\mathrm{CuCl}_{2} \rightarrow \mathrm{ArHCl}^{*}+\mathrm{CuCl} \\
& \mathrm{ArHCl}^{*}+\mathrm{CuCl}_{2} \rightarrow \mathrm{ArCl}+\mathrm{CuCl}+\mathrm{HCl} \\
& 4 \mathrm{HCl}+\mathrm{O}_{2} \rightarrow 2 \mathrm{Cl}_{2}+\mathrm{H}_{2} \mathrm{O}
\end{aligned}
$$

It has been suggested in several studies that the de novo synthesis of PCNs occurs in MSWIs, from the degradation of polycyclic aromatic hydrocarbons followed by their repeated chlorination (Iino et al., 1999; Weber et al., 2001). A considerable amount of carbonaceous material was found in the fly ash used in this study, so a similar PCN formation pathway may have been feasible. A large amount of chlorine was found in the fly ash $(8.97 \%$ by weight, shown in Table S2), but we were unable to determine if the chorine species present in the matrix caused the PCNs to be formed through chlorination reactions. Eqs. (1)-(3) show that chlorination reactions can produce gaseous inorganic chlorine. Therefore, detecting gaseous inorganic chlorine in our reaction system would offer strong evidence for the occurrence of chlorination reactions. We tested this hypothesis by attempting to detect inorganic chlorine in the system. The amount of gaseous inorganic chlorine produced in Experiment 1 was determined by ion chromatography (the analytical method is described in Supporting Information). The total amount of chlorine produced was $6025 \pm 709 \mu \mathrm{g}$, and the presence of such a lot of gaseous inorganic chlorine confirmed that the PCNs could have been produced through the chlorination pathway.

The presence of considerable amounts of naphthalene, the suggested starting material, would prove that the chlorination pathway could have occurred. Therefore, we first analyzed the initial fly ash for naphthalene by gas chromatography coupled with mass spectrum (GC-MS) (the method used is described in Supporting Information). However, insufficient naphthalene $(0.12 \pm 0.01 \mu \mathrm{g})$ was found in the initial fly ash $(0.2 \mathrm{~g})$ to produce all of the PCNs that were formed in the tests. It was therefore natural to wonder if the naphthalene was formed when the fly ash was heated, by the decomposition of the carbonaceous macromolecules that were found in large amounts in the initial fly ash. We analyzed the product of the thermal reactions for naphthalene, again taking Experiment 1 as an example. We found that $6.19 \pm 3.32 \mu \mathrm{g}$ of naphthalene was produced during Experiment 1, meaning that more than 50 times more naphthalene was produced when the fly ash was heated than was present in the initial fly ash. This strongly supports the assumption that naphthalene was formed in considerable amounts during the thermal experiments. In $0.2 \mathrm{~g}$ of fly ash matrix, $6.19 \mu \mathrm{g}$ of naphthalene was produced in Experiment 1 , so the mass concentration of the produced naphthalene was calculated to be $30.38 \mu \mathrm{g} \mathrm{g}^{-1}$ fly ash. The mass concentration of naphthalene $\left(30.38 \mu \mathrm{g} \mathrm{g}^{-1}\right)$ is lower than that of the $\Sigma$ PCNs $\left(57.33 \mu \mathrm{g} \mathrm{g}^{-1}\right)$. Compared with the mass concentration, molar concentration was more common and reliable in the discussion of kinetic reaction. Then we calculated the molar concentration of the produced naphthalene and $\Sigma$ PCNs. The molar concentration of naphthalene was calculated to be $237.0 \mathrm{nmol} \mathrm{g}^{-1}$, which was much higher than those of produced $\Sigma$ PCNs $\left(160.2 \mathrm{nmol} \mathrm{g}^{-1}\right.$ ). Therefore, the gap between the mass concentration of naphthalene and PCNs was mainly due to the contribution from the chlorine atom of PCNs rather than that from naphthalene skeleton, and the formed naphthalene was sufficient for chlorination reaction producing $\Sigma$ PCNs.

In conclusion, we propose a mechanism for the formation of PCNs in thermal treatments. The carbon residues first fragment, supplying naphthalene, then the unsubstituted naphthalene is chlorinated by chlorine supplied by the fly ash itself, yielding 


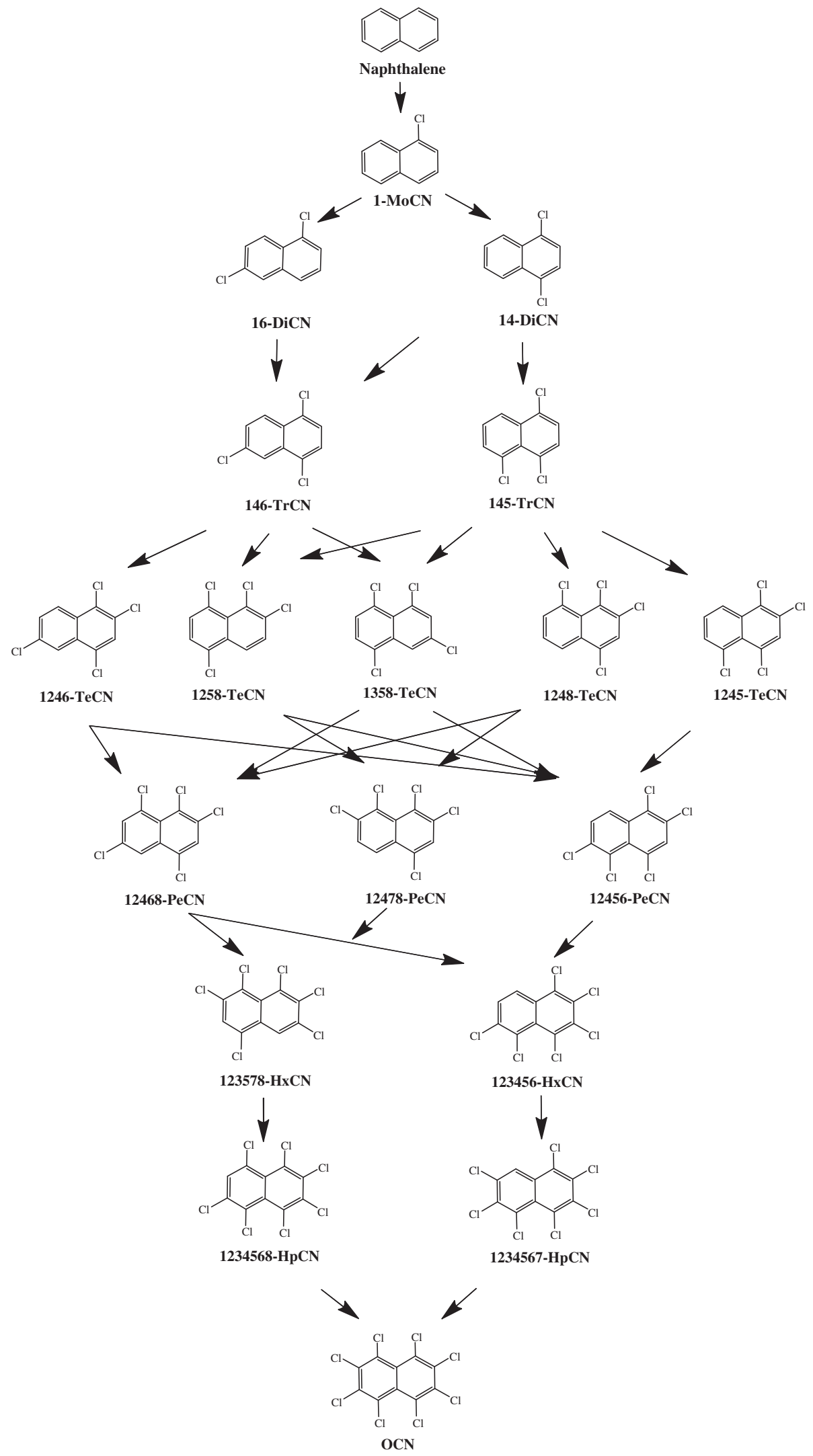

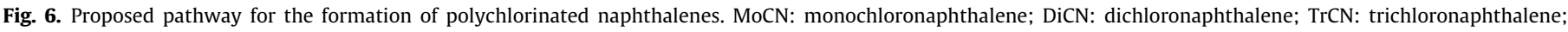
TeCN: tetrachloronaphthalene; PeCN: pentachloronaphthalene; HxCN: hexachloronaphthalene; HpCN: heptachloronaphthalene; OCN: octachloronaphthalene. 
monochloronaphthalene and more chlorinated PCN homologs. We postulated a chlorination pathway from naphthalene to octa-CN based on the dominant congeners found within each homolog, and this pathway is shown in Fig. 6. Despite the results of this study suggesting that the chlorination reaction may be important in the formation of PCNs, the contribution of de novo synthesis cannot be neglected because, as mentioned above, the de novo synthesis of PCNs was found to be possible in previous studies (Benfenati et al., 1991; Iino et al., 1999; Imagawa and Lee, 2001; Weber et al., 2001). It seems likely that the large amounts of PCNs formed in thermal treatments are not formed through a single pathway but rather through a combination of chlorination reactions and de novo synthesis (Oh et al., 2007; Jansson et al., 2008; Liu et al., 2014). Further studies will be required to identify other formation pathways that may be involved.

\section{Conclusion}

We performed a series of laboratory-scale experiments using fly ash as the reaction matrix to simulate the thermal formation of PCNs in the post-zone of a secondary copper smelter. Under different thermal conditions, unexpectedly high concentrations of PCNs about two orders of magnitude higher than the initial PCNs were detected. Kinetic examination demonstrated that less chlorinated homologs seemed to favor $350^{\circ} \mathrm{C}$ and more chlorinated homologs seemed to favored higher temperature. Most of the homologs could be formed within a short time period, while octa-CN did not appear to reach equilibrium of formation and degradation within our investigated reaction time. The de novo synthesis of polychlorinated naphthalenes following a consecutive chlorination of naphthalene molecules was suggested to be an important pathway for the formation of PCNs. This study will provide valuable information that improves our understanding of the mechanism and kinetics by which PCNs are formed during metallurgical processes and offer important improvements in our ability to control and minimize the unintentional formation and emission of PCNs.

\section{Acknowledgments}

We gratefully acknowledge support from the National Natural Science Foundation of China (Nos. 21037003, 21107123 and 21321004) and the China Postdoctoral Science Foundation (2013M540151).

\section{Appendix A. Supplementary material}

Detailed characterization information of the reaction matrix, setting of the reaction conditions, Pearson coefficients between each of the produced polychlorinated naphthalene homologs, schematic of the reaction system, structure and commonly used numbering system of PCN congeners, and the description of analysis method for inorganic chlorine and naphthalene are provided as supporting information. Supplementary data associated with this article can be found, in the online version, at http://dx.doi.org/ 10.1016/j.chemosphere.2014.09.052.

\section{References}

Abad, E., Caixach, J., Rivera, J., 1999. Dioxin like compounds from municipal waste incinerator emissions: assessment of the presence of polychlorinated naphthalenes. Chemosphere 38, 109-120.

Addink, R., Olie, K., 1995. Mechanisms of formation and destruction of polychlorinated dibenzo-p-dioxins and dibenzofurans in heterogeneous systems. Environ. Sci. Technol. 29, 1425-1435.

Altwicker, E.R., Konduri, R., Lin, C., Milligan, M.S., 1992. Rapid formation of polychlorinated dioxins furans in the post combustion region during heterogeneous combustion. Chemosphere 25, 1935-1944.
Ba, T., Zheng, M.H., Zhang, B., Liu, W.B., Su, G.J., Liu, G.R., Xiao, K., 2010. Estimation and congener-specific characterization of polychlorinated naphthalene emissions from secondary nonferrous metallurgical facilities in China. Environ. Sci. Technol. 44, 2441-2446.

Benfenati, E., Mariani, G., Fanelli, R., Zuccotti, S., 1991. Denovo synthesis of PCDD, PCDF, PCB, PCN and PAH in a pilot incinerator. Chemosphere 22, 1045-1052.

Blankenship, A.L., Kannan, K., Villalobos, S.A., Villeneuve, D.L., Falandysz, J., Imagawa, T., Jakobsson, E., Giesy, J.P., 2000. Relative potencies of individual polychlorinated naphthalenes and Halowax mixtures to induce Ah receptormediated responses. Environ. Sci. Technol. 34, 3153-3158.

Chin, Y.T., Lin, C., Chang-Chien, G.P., Wang, Y.M., 2011. PCDD/Fs formation catalyzed by the copper chloride in the fly ash. J. Environ. Sci. Health, Part A 46, 465-470.

Cobo, M., Gálvez, A., Conesa, J.A., Montes de Correa, C., 2009. Characterization of fly ash from a hazardous waste incinerator in Medellin, Colombia. J. Hazard. Mater. $168,1223-1232$.

Falandysz, J., 1998. Polychlorinated naphthalenes: an environmental update. Environ. Pollut. 101, 77-90.

Gullett, B.K., Bruce, K.R., Beach, L.O., Drago, A.M., 1992. Mechanistic steps in the production of PCDD and PCDF during waste combustion. Chemosphere 25, 1387-1392.

Hanberg, A., Waern, F., Asplund, L., Haglund, E., Safe, S., 1990. Swedish dioxin survey: determination of 2,3,7,8-TCDD toxic equivalent factors for some polychlorinated biphenyls and naphthalenes using biological tests. Chemosphere 20,1161-1164.

Hatanaka, T., Kitajima, A., Takeuchi, M., 2004. Role of copper chloride in the formation of polychlorinated dibenzo-p-dioxins and dibenzofurans during incineration. Chemosphere 57, 73-79.

Hu, J., Zheng, M., Liu, W., Li, C., Nie, Z., Liu, G., Zhang, B., Xiao, K., Gao, L., 2013. Characterization of polychlorinated naphthalenes in stack gas emissions from waste incinerators. Environ. Sci. Pollut. Res. 20, 2905-2911.

Iino, F., Imagawa, T., Takeuchi, M., Sadakata, M., 1999. De novo synthesis mechanism of polychlorinated dibenzofurans from polycyclic aromatic hydrocarbons and the characteristic isomers of polychlorinated naphthalenes. Environ. Sci. Technol. 33, 1038-1043.

Imagawa, T., Lee, C.W., 2001. Correlation of polychlorinated naphthalenes with polychlorinated dibenzofurans formed from waste incineration. Chemosphere 44, 1511-1520.

Jansson, S., Fick, J., Marklund, S., 2008. Formation and chlorination of polychlorinated naphthalenes (PCNs) in the post-combustion zone during MSW combustion. Chemosphere 72, 1138-1144.

Kim, D.H., Mulholland, J.A., Ryu, J.Y., 2005. Formation of polychlorinated naphthalenes from chlorophenols. Proc. Combust. Inst. 30, 1245-1253.

Kim, D.H., Mulholland, J.A., Ryu, J.-Y., 2007. Chlorinated naphthalene formation from the oxidation of dichlorophenols. Chemosphere 67, S135-S143.

Lerche, D., Van de Plassche, E., Schwegler, A., Balk, F., 2002. Selecting chemical substances for the UN-ECE POP Protocol. Chemosphere 47, 617-630.

Liu, G.R., Zheng, M.H., Lv, P., Liu, W.B., Wang, C.Z., Zhang, B., Xiao, K., 2010. Estimation and characterization of polychlorinated naphthalene emission from coking industries. Environ. Sci. Technol. 44, 8156-8161.

Liu, G.R., Zheng, M.H., Du, B., Nie, Z.Q., Zhang, B., Hu, J.C., Xiao, K., 2012a. Identification and characterization of the atmospheric emission of polychlorinated naphthalenes from electric arc furnaces. Environ. Sci. Pollut. Res. 19, 3645-3650.

Liu, G.R., Zheng, M.H., Du, B., Nie, Z.Q., Zhang, B., Liu, W.B., Li, C., Hu, J.C., 2012 b. Atmospheric emission of polychlorinated naphthalenes from iron ore sintering processes. Chemosphere 89, 467-472.

Liu, G.R., Cai, Z.W., Zheng, M.H., 2014. Sources of unintentionally produced polychlorinated naphthalenes. Chemosphere 94, 1-12.

Milligan, M.S., Altwicker, E., 1993. The relationship between de novo synthesis of polychlorinated dibenzo-p-dioxins and dibenzofurans and low-temperature carbon gasification in fly ash. Environ. Sci. Technol. 27, 1595-1601.

Nie, Z., Zheng, M., Liu, W., Zhang, B., Liu, G., Su, G., Lv, P., Xiao, K., 2011. Estimation and characterization of PCDD/Fs, dl-PCBs, PCNs, $\mathrm{HxCBz}$ and PeCBz emissions from magnesium metallurgy facilities in China. Chemosphere 85, 1707-1712.

Noma, Y., Yamamoto, T., Sakai, S.-I., 2004. Congener-specific composition of polychlorinated naphthalenes, coplanar PCBs, dibenzo-p-dioxins, and dibenzofurans in the halowax series. Environ. Sci. Technol. 38, 1675-1680.

Oh, J.-E., Gullett, B., Ryan, S., Touati, A., 2007. Mechanistic relationships among PCDDs/Fs, PCNs, PAHs, CIPhs, and CIBzs in municipal waste incineration. Environ. Sci. Technol. 41, 4705-4710.

Pekárek, V., Weber, R., Grabic, R., Šolcová, O., Fišerová, E., Šyc, M., Karban, J., 2007. Matrix effects on the de novo synthesis of polychlorinated dibenzo-p-dioxins, dibenzofurans, biphenyls and benzenes. Chemosphere 68, 51-61.

Ryu, J.-Y., Kim, D.-H., Jang, S.-H., 2013. Is chlorination one of the major pathways in the formation of polychlorinated naphthalenes (PCNs) in municipal solid waste combustion? Environ. Sci. Technol. 47, 2394-2400.

Schneider, M., Stieglitz, L., Will, R., Zwick, G., 1998. Formation of polychlorinated naphthalenes on fly ash. Chemosphere 37, 2055-2070.

Stanmore, B.R., 2004. The formation of dioxins in combustion systems. Combust. Flame 136, 398-427.

Stieglitz, L., Zwick, G., Beck, J., Roth, W., Vogg, H., 1989. On the de-novo synthesis of $\mathrm{PCDD} / \mathrm{PCDF}$ on fly ash of municipal waste incinerators. Chemosphere 18, 12191226.

Takaoka, M., Shiono, A., Nishimura, K., Yamamoto, T., Uruga, T., Takeda, N., Tanaka, T., Oshita, K., Matsumoto, T., Harada, H., 2005. Dynamic change of copper in fly ash during de novo synthesis of dioxins. Environ. Sci. Technol. 39, 5878-5884. 
Tsai, J.-H., Lin, K.-H., Chen, C.-Y., Ding, J.-Y., Choa, C.-G., Chiang, H.-L., 2007. Chemical constituents in particulate emissions from an integrated iron and steel facility. J. Hazard. Mater. 147, 111-119.

Villeneuve, D., Kannan, K., Khim, J., Falandysz, J., Nikiforov, V., Blankenship, A. Giesy, J., 2000. Relative potencies of individual polychlorinated naphthalenes to induce dioxin-like responses in fish and mammalian in vitro bioassays. Arch. Environ. Contam. Toxicol. 39, 273-281.

Weber, R., Iino, F., Imagawa, T., Takeuchi, M., Sakurai, T., Sadakata, M., 2001. Formation of PCDF, PCDD, PCB, and PCN in de novo synthesis from PAH: mechanistic aspects and correlation to fluidized bed incinerators. Chemosphere 44, 1429-1438. 